\title{
Narrative Explanations of Action. Narrative Identity with Minimal Requirements
}

\author{
Deniz A. Kaya ${ }^{1}$ (D)
}

Accepted: 3 September 2021

(c) The Author(s) 2021

\section{Introduction}

One type of theory that has been gaining popularity for some time is that of the narrative structure of personal identity. I will examine theories of this kind in the following.

A narrative approach of personal identity has some advantages over competing approaches. For example, narrative approaches to identity can explain certain problems regarding neurosurgical interventions. For example, in the context of such medical interventions, it may not be sufficient to preserve the numerical identity of the patient. Instead, interventions of this kind must also preserve their narrative identity so that their so-called inner story can persist. ${ }^{1}$ This is because, it could be argued, a person's narrative identity is linked to their authenticity in a way that numerical identity is not. ${ }^{2}$

First, I will explore some concerns about the notion of narrativity in the context of personal identity expressed by Peter Lamarque. ${ }^{3}$ I will focus on the minimal conditions he identifies for narrativity and why, according to him, the concept of narrativity in this minimal sense cannot tell us anything about our personal identity.

I will then examine the concept of teleological explanations of action. I will show that the causal theory of action is confronted with the problem of deviating causal chains, which it seems unable to solve due to the irreducibility of teleological explanations of action to causal ones. I will then elaborate some characteristics of teleological explanations of action.

\footnotetext{
${ }^{1}$ See N. S. Jecker and A. L. Ko, "Is That the Same Person? Case Studies in Neurosurgery," American Journal of Bioethics Neuroscience, 8 (2017): 160-170.

2 See Joseph M. Vukov, "Why Narrative Identity Matters: Preserving Authenticity in Neurosurgical Interventions," American Journal of Bioethics Neuroscience, 8 (2017): 187.

3 See Peter Lamarque, "On Not Expecting Too Much from Narrative," Mind \& Language, 19 (2004): 393-408.
}

Deniz A. Kaya

deniz_kaya@mail.de

1 Department of Philosophy, University of Stuttgart, Stuttgart, Germany 
With the help of these features, I will then argue that teleological explanations of action fulfil Lamarque's minimal conditions for narrativity. I will show to what extent we can understand them as narrative explanations of action and what relevance the resulting stories of our actions and lives have for us. Above all, I will argue that narrative explanations of action play a central role in enabling us to conceive ourselves as rational agents and that narrativity is therefore, contrary to Lamarque's assertion, anything but trivial in relation to our personal identity, even in its minimal sense.

\section{Against Narrativity in Personal Identity}

In On Not Expecting Too Much from Narrative, Lamarque argues that the concept of narrativity in the context of theories of personal identity should not raise too many expectations. This is because, according to Lamarque, either the concept of narrativity would be able to tell us a lot of interest about the nature of our selves. However, the conditions of narrativity in this case are so high that they cannot be met by narrative theories of our selves. Alternatively, according to Lamarque, the conditions of the concept of narrativity are so weak that they are easily met. In that case, however, the fact that we understand ourselves as narrative cannot tell us much about our selves. ${ }^{4}$ In what follows, I am interested in these minimal conditions of narrativity identified by Lamarque. What exactly do they consist of?

First, Lamarque points out that the term 'narrative' is ambiguous, possessing a "three-way product-act-object ambiguity". 5 Thus, the term 'narrative' can be understood as a specific product, i.e. a specific story. However, 'narrative' can also be understood in the sense of the act of narrating. Thirdly, 'narrative' can also be understood as a particular text, i.e. a particular instantiation of a narrative in the first sense of the word. ${ }^{6}$ In the context of his analysis, Lamarque is primarily interested in the first sense of 'narrative'.

Lamarque points out three minimal conditions for stories:

(1) Stories are told, they are not simply found.

(2) In the context of a story, at least two events are presented and related to each other.

(3) The relationship in which these events are presented must have a temporal component. $^{7}$

In addition to these minimal conditions, Lamarque lists four further properties of narratives, all of which derive from the fact that narrativity consists solely in formal rather than content properties. This means that narratives can be

\footnotetext{
4 See ibid., p. 393.

5 Ibid., p. 394.

6 See ibid., pp. 394-395.

7 See ibid., p. 394.
} 
(4) about both real and imagined entities,

(5) true, false or even non-true; and

(6) used for a range of purposes. ${ }^{8}$

A final point that Lamarque makes is that a narrative

(7) can only be given by a narration. ${ }^{9}$

Being a narrative (or 'being narrative') in this minimal sense of narrativity is exhausted in (1) setting (2) several events in (3) a temporal relation to each other.

Within the framework of these minimal conditions, personal identity can be understood as narrative as well. If we want to comprehend the actions of an agent, we must locate them in their temporal and social context, as Alasdair MacIntyre says. ${ }^{10}$ Therefore "[n]arrative history of a certain kind turns out to be the basic and essential genre for the characterization of human actions." ${ }^{11}$ Lamarque admits that MacIntyre seems to be correct here in describing this order of certain actions of an agent and other events as narrative:

A narrative, as we have seen and as MacIntyre recognizes, is the depiction of an ordered sequence of events, so representing actions in a causal and temporal sequence-seemingly the most straightforward if not the only way to do so-is in this minimal sense indeed to represent them in a narrative. ${ }^{12}$

Theories of narrative identity are problematic because they usually go beyond this representation of events in a certain temporal order and therefore operate with a stronger concept of narrativity. This is also the case with MacIntyre, who, according to Lamarque, reads more and more into the concept of narrativity. He identifies two fundamental problems with MacIntyre. First, he moves from talking about narratives to talking about genres. In doing so, he suggests not only a proximity of personal identity to narrativity, but also to literariness. ${ }^{13}$ However, this transition does not initially seem to be justified by the temporal order of (life) events as such.

Secondly, MacIntyre is not talking about which genres narratives belong to, but which genres lives belong to. "This merging of life and narrative is a mistake. A narrative, being a story, must be narrated, but a life need not be narrated." 15 This superimposition is accompanied by the fact that the initially very weak concept of narrativity now becomes charged with other properties, such as fictionality. It is

\footnotetext{
8 See ibid.

9 See ibid., 395.

10 See ibid., p. 402.

11 Alasdair MacIntyre, After Virtue: a Study in Moral Theory (London/New York: Bloomsbury Academic, 2011 [1985]), p. 242. The page numbers here and in the following (where applicable) refer to the reprint.

12 Lamarque, op. cit., p. 402.

13 See ibid.

14 See MacIntyre, op. cit., p. 245.

15 Lamarque, op cit., p. 402.
} 
correct that when we tell stories about ourselves or our lives, we are capable of adding certain events that never happened to the narrative of our selves or of embellishing certain events. However, it seems evident that this is not necessarily the case. According to Lamarque, this can also be seen in the dependency of the existence of the respective characters of the narration on the narration:

Fictional characters do owe their identities to narratives at a deep level; what they are is what the narratives say they are [...]. But none of the basic premises in, say, MacIntyre's theory implies any such thing about real persons. The truth is more prosaic. We do tell stories about ourselves but more often than not they are mundane, fragmented, inconsequential, and for the most part blandly true rather than grandly inventive. ${ }^{16}$

What is also apparent here: The idea of life as a narrative suggests that our life is a self-contained story. But this degree of self-containment is almost never met by the narratives of our actual lives. ${ }^{17}$

Finally, the narrator problem: every narrative requires a narrator. Only then is the narrative constituted. To be told is a necessary condition of every narrative. However, this does not seem to be the case with our selves. If we do not have a story about ourselves, should we then conclude that we do not exist as a "subject of thought and action"? ${ }^{18}$ Clearly this is not the case. Therefore, we have to precede our own story. However, this implies that our identity cannot be constituted by a story or the narration of such a story.

In a nutshell, then, if one wants to speak of narrative identity, one can only do so in terms of such a weak notion of narrativity, namely in terms of the minimal conditions (1)-(3), that it does not include much more than the temporal order of our life events. Such a concept of narrativity, however, seems to be too weak to tell us anything of interest about our selves, since it is precisely this form of narrativity that Strawson calls trivial:

What do I mean by [...]trivial? Well, if someone says, as some do, that making coffee is a narrative that involves Narrativity, because you have to think ahead, do things in the right order, and so on, and that everyday life involves many such narratives, then I take it the claim is trivial. ${ }^{19}$

In what follows, I am interested in precisely this form of trivial narrativity. I will argue for the case that-under certain assumptions-it is neither as trivial as Strawson assumes, nor can it tell us as little about ourselves as Lamarque believes. To do this, however, I must first say a few things about teleological explanations of action.

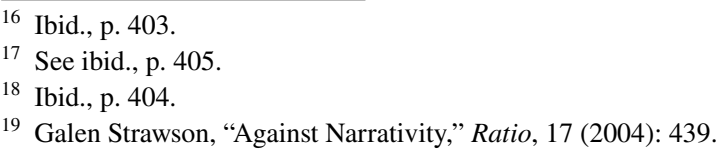




\section{Teleological Explanations of Action}

The standard view on explanations of action is causal in nature. ${ }^{20}$ Representatives of this view, causalists, hold that explanations of actions are certain explanations of the causal history of the events we call actions. The standard version of this view, which was inspired by Donald Davidson, is the one that holds that actions can be explained by their causes, i.e. reasons, and that these reasons consist in a Belief-Desire-Pair. ${ }^{21}$ It thus states, first of all:

(BD) An agent has only performed an action for a reason if this reason is composed of a desire for the goal of the action and the belief that the action is appropriate to realise this goal. ${ }^{22}$

In addition to a whole range of reasons an agent may have had for acting, according to the Davidsonian causalist, he always had a primary reason and this is the cause of the action. ${ }^{23}$ There are basically two groups of alternative approaches: on the one hand, volition theories (for example, the one by Harry Frankfurt), which I will not discuss further in the following, and on the other hand, teleological theories of action, which were to a considerable extent influenced by G. E. M. Anscombe. ${ }^{24}$

Teleologists believe that actions can (and should) be explained teleologically. This means that actions always consist of goal-directed behaviour and that explanations of actions must always be formulated in terms of these goals. That our actions can be explained teleologically is something that few people seriously want to deny. However, teleologists usually deny the causalists' claim that actions can (also) be described in causal terms and argue instead, within the framework of an "anti-causalist teleologism" 25 , that the only adequate explanations of actions are teleological in nature.

I will now begin by discussing why we should at least consider teleological theories of action as a serious alternative. In doing so, I cannot, of course, provide a full argument here that will settle the question of the ultimately appropriate type of explanations of action or the irreducibility of teleological explanations to causal

\footnotetext{
${ }^{20}$ In the following, I use the terms explanations of action and descriptions of action synonymously. There are indeed differences between descriptions and explanations. However, these are negligible for my line of argument here.

21 See Donald Davidson, “Actions, Reasons, and Causes," in Donald Davidson (ed.), Essays on Actions and Events (Oxford: Oxford University Press, 2001 [1963]), 3-20, p. 3-4.

22 Christoph Horn and Guido Löhrer, "Die Wiederentdeckung teleologischer Handlungserklärungen," in Christoph Horn and Guido Löhrer (ed.), Gründe und Zwecke. Texte zur aktuellen Handlungstheorie (Frankfurt a. M.: Suhrkamp, 2010), 7-45, p. 18; my translation. Causal approaches of the explanation of action can already be found in Aristotle: "The origin of action-its efficient, not its final cause-ist choice, and that of chioce is desire and reasoning with a view to an end" (NE VI, 2; 1139a31-33).

23 See Davidson, "Actions, Reasons, and Causes", op. cit., p. 4.

24 See G. E. M. Anscombe, Intention (Cambridge, MA/London: Harvard University Press, 2000 [1957]). For Frankfurt's theory of action see Harry G. Frankfurt, "The problem of action," American Philosophical Quarterly, 15 (1978): 157-162.

25 Alfred R. Mele, “Goal-Directed Action: Teleological Explanations, Causal Theories, Deviance," Philosophical Perspectives, 14 (2000): 279.
} 
ones. Rather, I will briefly mention a few points that show why we have reason to at least seriously consider teleological explanations of action. These are, as I argue below, also interesting regarding the adequacy of narrative accounts of personal identity.

\section{The Renaissance of Teleological Explanations of Action}

The renaissance of teleological explanations of action was above all a reaction to the problems with which causalists were increasingly confronted. I will briefly explain the most crucial problem of causal explanations, namely that of deviant causal chains, using two examples:

Bad marksman: Someone, J, wants to kill his former best friend, K, out of revenge and because of various moral missteps by $\mathrm{K}$, by shooting him. However, the bullet misses $\mathrm{K}$ by far. However, in the process it frightens a horde of wild boars, which stampede $\mathrm{K}$ in their panic. ${ }^{26}$

Clearly, this is a problem for the causalist. After all, if $\mathbf{J}$ had the desire to kill $\mathrm{K}$ and the belief that shooting a gun in K's direction was an appropriate means of fulfilling this desire, we must regard the killing of K as J's action. Nevertheless, we would not want to claim that J killed $\mathrm{K}$ under the given circumstances - at least not in the sense in which we would describe the killing of $\mathrm{K}$ by trampling wild boars as J's intentional action. In this case, we are dealing with a secondary deviation of a causal chain. This means that the causal chain only took a different path than originally intended after the action had already begun: Only after $\mathrm{J}$ fired the pistol at $\mathrm{K}$ did the bullet miss its actual target and frighten the wild boar horde, whose stampede in turn led to K's death. The situation is different with primary deviations:

Nervous philosopher: A philosopher intends to distract his all too annoying interview partner by spilling his water glass. However, this causes him to be so nervous that he accidentally spills his water glass and thereby distracts his interview partner. ${ }^{27}$

In this case, again, the causalist has problems explaining the difference between this kind of behaviour compared to intentional behaviour, i.e. actions. The philosopher desired to distract his interview partner and had the belief that he would achieve this by spilling his glass of water. But what is the difference between the two cases, the intentional spilling on the one hand and the spilling due to nervousness on the other? In both cases, the respective Belief-Desire-Pair is present (due to the philosopher's intention). However, in this case we would not want to speak of

\footnotetext{
26 The original example is given in Donald Davidson, "Freedom to Act," in Donald Davidson (ed.), Essays on Actions and Events (Oxford: Oxford University Press, 2001 [1973]), 63-81, p. 78.

27 The example of the nervous philosopher can be found in Alfred R. Mele, Springs of Action (New York: Oxford University Press, 1992), p. 182. Davidson already gives a similar example of this in his "Freedom to Act," op. cit., p. 79.
} 
an intentional doing, i.e. an action. What exactly is the problem of deviant causal chains in the sense of primary deviation?

Causalists assume that teleological explanations of action can be reduced to causal ones. According to the causalist, the intended behaviour of the philosopher can be described as such: That the philosopher's aim was to distract his interview partner simply means that he had the intention of distracting him. This intention, in turn, can be interpreted as the cause of his behaviour: by spilling his water glass, he fulfils his intention to distract his interview partner, which his action has caused. A causal reduction of such behaviour in general could thus be stated roughly as follows:

(CR1): A had the intention to $\psi$ and this caused A to $\varphi .^{28}$

With this simple reduction of teleological explanations of action to causal ones, however, we run into the problem of deviant causal chains. A causal explanation would also have to be able to explain the difference between the behaviour of the philosopher if he had not been nervous and his behaviour in the example described. An obvious specification of the causal reduction could therefore look like this:

(CR2): A had the intention to $\psi$ and this immediately caused A to $\varphi .^{29}$

This could explain the difference between nervous behaviour and non-nervous behaviour. For nervousness and not the intention to spill the water glass was the immediate cause of the philosopher's behaviour. However, this form of causal reduction again gives rise to some problems. Firstly, (CR2) seems to be too strong. If I have the intention to check the fridge for the rest of chocolate cake and then start moving, my intention, realised as a brain state, does not directly cause me to start moving. Instead, an electrochemical signal must first get from my brain to my arms and legs so that they perform the movements necessary to walk into the kitchen and open the fridge door. So even with perfectly normal actions, intention does not immediately cause the corresponding actions. ${ }^{30}$

Alfred Mele responds by claiming that the action already begins in the brain. ${ }^{31}$ However, this gives rise to the following issue: If the action does already begin in the brain, i.e. immediately after the intention, which is, after all, the cause of the corresponding action, why are we not able to claim that the intention is the cause of the-neurophysiologically realised-nervousness, which in turn causes further physiological events - certain electrochemical signals to the hands of the nervous philosopher-which in turn cause the hand movements that lead to the spilling of the water glass? It seems that even with this form of causal reduction, we ultimately

\footnotetext{
28 See Scott Sehon, "Deviant Causal Chains and the Irreducibility of Teleological Explanation," Pacific Philosophical Quarterly, 78 (1997): 196.

29 See ibid., p. 199.

30 See ibid., p. 200.

31 See Mele, Springs of Acion, op. cit., p. 202.
} 
cannot understand the difference between actual actions and such behaviour as that of the nervous philosopher. ${ }^{32}$

One way of dealing with problems of this kind would be to simply rule out conditions such as nervousness, resulting in the following attempt of causal reduction:

(CR3): A had the intention to $\psi$, this immediately caused A to $\varphi$ and it is not the case that a state of nervousness was a necessary causal factor. ${ }^{33}$

Such an attempt to reduce teleological explanations of action to causal ones is in some ways disappointing, because it sounds very much like an ad hoc solution. Rather than explaining what exactly the problem is or why it does not actually exist, cases of this kind are simply not considered further. But an even more serious problem arises. Sometimes even if states of agitation are present we want to talk about actions:

Excited weightlifter: A weightlifter takes part in a competition. He firmly believes that he can lift the weight in front of him and when he tries, he succeeds. But in fact, just before he tries to lift the weight, he is overcome by a touch of nervousness. Only this nervousness allowed him to actually lift the weight. In a non-nervous state, he would not have been able to lift the weight. ${ }^{34}$

To claim that the weightlifter did not act when lifting the weight would seem absurd. But then we face the problem that states of agitation cannot simply be ruled out in the context of causal reductions. In response, Mele suggests that physiological states such as that of agitation may no longer count as part of the action-and thereby constitute a causal gap between the intention and the behaviour, i.e. ensure that the intention is no longer the immediate cause of the behaviour-precisely when they result in the agent's behaviour no longer being subject to the agent's control or direction:

(CR4): A had the intention to $\psi$, this immediately caused A to $\varphi$, and the intention directed A's $\varphi$-ing and sustained it. ${ }^{35}$

But even this reduction is ultimately not satisfactory. Scott Sehon identifies two problems: firstly, the requirement of directing the $\varphi$-ing over the entire period of the action appears to be too strong. If I have the intention of typing a text in front of me, it may be that-even though this intention may well have directed my finger movements in the beginning-I eventually switch to no longer directing my fingers at some point and still continue to type the text "rather automatically" 36 . Directing my movements, according to Sehon, does not seem necessary. Here, however, Sehon

\footnotetext{
32 See Sehon, "Deviant Causal Chains and the Irreducibility of Teleological Explanation," op. cit., p. 200.

33 See ibid., 202.

34 This expample can be found in George M. Wilson, The Intentionality of Human Action (Stanford: Stanford University Press, 1989), p. 252.

35 See Sehon, "Deviant Causal Chains and the Irreducibility of Teleological Explanation," op. cit., p. 203.

36 Ibid.
} 
himself does not seem to realise that directing is indeed of crucial importance in this example. If I continue to type 'rather automatically', a case seems to have occurred that we would possibly no longer describe as action at all. My behaviour admittedly still makes sense (I still type the text in front of me and don't just type random combinations of letters). But similar to my steering and shifting behaviour in the car on an empty, straight country road, this no longer seems to be an action in a demanding sense.

The second problem Sehon identifies is more serious: Concepts such as controlling and directing already seem to be teleological concepts themselves and in this respect they have no place within the framework of a reduction of the telological to the causal. "When an agent $\varphi$ 's in order to $\psi$, she directs her behavior towards that outcome, i.e. she guides it in accordance with the given purpose." 37 Therefore, even recourse to terms such as directing and controlling cannot ultimately save a causal reduction. ${ }^{38}$

Certainly, there are other strategies that could be used to try to show that a reduction of teleological explanations of action to causal ones is possible. ${ }^{39}$ Nevertheless: All causalists are confronted with the problem of deviant causal chains (and other problems) for the time being, and a solution to the problem within the framework of causal explanations of action is at least not obvious. We should therefore at least consider teleological explanations of action as an option to be taken seriously.

I have not yet explained what exactly teleological explanations of action are. I shall do so in the following section before proceeding to explain what they have to do with narrative conceptions of personal identity.

\section{What are Teleological Explanations of Action?}

Teleological explanations of action are those that, in order to explain certain actions of an agent, refer to the ends pursued by that agent and the extent to which the agent assumed that a certain action would get him closer to that end. So my going to the fridge can be explained as going to the fridge in order to get a piece of chocolate

\footnotetext{
37 Ibid.

38 The fact that the concepts of directing and controlling are teleological concepts also is the reason why I am not concerned here with volitional explanations of action in Frankfurt's sense. According to him, the decisive thing about actions is that the agent has control over or directs his bodily movements during the action: "What is not merely pertinent but decisive, indeed, is to consider whether or not the movements as they occur are under the person's guidance. It is this that determines whether he is performing an action" (Frankfurt, op. cit., p. 158).

39 One possible strategy would be trying to explain that intentions to are realised in certain brain states, which in turn explain As -ing strongly differentially. See Christopher Peacocke, Holistic Explanation: Action, Space, Interpretation (New York: Oxford University Press, 1979), pp. 79-80; for an analysis and criticism of this attempt, see Sehon, "Deviant Causal Chains and the Irreducibility of Teleological Explanation," op. cit., pp. 204-212. See Berent Enç, "Causal Theories and Unusual Causal Pathways", Philosophical Studies, 55 (1989): 231-261 for a survey of the problem of divergent causal chains not only with respect to actions but with respect to causal theories in general. I thank an anonymous reviewer for pointing out to me the latter.
} 
cake. Generally, teleological explanations of action have such an 'in order to'-structure. Formulated in general terms:

(TE1): A $\varphi$-s in oder to $\psi .^{40}$

Explanations of action can also be formulated differently, so that they initially appear to be causal explanations. But obviously explanations like "I went to the fridge because I wanted chocolate cake" can be traced back to teleological ones: "I went to the fridge in order to get chocolate cake". The teleologist regards the concept of goal-directedness in the context of action as fundamental and irreducible to causal concepts. $^{41}$

The concept of teleological explanation of action was considerably influenced by Anscombe's enquiry into the concept of intention. ${ }^{42}$ According to her, we can always ask the question about the purpose or the (non-causally understood) reasons for the action, the Question of 'Why?'. ${ }^{3}$ Through the Question of 'Why?', we aim to embed certain descriptions of action in a broader teleological (i.e. non-causal) context. This embedding is possible because we can put different descriptions of one and the same action into a teleological order within which purpose-means (or partwhole) relations prevail between the different descriptions of the action. ${ }^{44}$ Here is an example:

Pumping man: A man pumps drinking water that he has previously poisoned into a tank that supplies a nearby house with water. With the help of the poisoned water he kills the residents of the house. ${ }^{45}$

The man's actions can now be described in different ways: (a) He poisons the residents of the house; (b) He pumps water into a tank; (c) He moves his arm; (d) He sets the lever mechanism of the pump in motion; (e) He kills the residents of the house. These different descriptions of action can now be ordered teleologically on the basis of the Question of 'Why?': (c) The man moves his arm.-Why?-(d) To set the lever mechanism of the pump in motion.-Why?-(b) To pump water into a tank.-Why? - (a) To poison the residents of the house.-Why?-(e) To kill the residents. The significance of each description of action becomes comprehensible in the context of a broader description.

This also demonstrates that some descriptions of what is going on do not qualify as descriptions of action. For instance, when pumping, the man will also cast shadows on the wall behind him. But he does not know about this and (therefore) does

\footnotetext{
${ }^{40}$ See for example Sehon, "Goal-Directed Action and Teleological Explanation," in Joseph Keim Campbell, Michael O'Rourke and Harry Silverstein (ed.), Causation and Explanation (Cambridge, MA/London: The MIT Press, 2007), 155-170, p. 155 and Horn and Löhrer, op. cit., p. 13.

41 See Sehon, "Goal-Directed Action and Teleological Explanation," op. cit., p. 155.

42 See Anscombe, op. cit.

43 See Fabian Börchers, "Handeln," in Daniel Martin Feige, Sebastian Ostritsch and Markus Rautzenberg (ed.), Philosophie des Computerspiels. Theorie-Praxis-Ästhetik (Stuttgart: J. B. Metzler, 2017), 97-122, p. 105.

44 See ibid., p. 105.

45 The example can in a similar form be found in Anscombe, op. cit., p. 37.
} 
not intend it. ${ }^{46}$ Even if casting shadows is an adequate description of what the man does, it is not an adequate description of his action, because it cannot be put in a wider teleological context. Or to put it differently: the Question of 'Why?' cannot be raised here meaningfully. The teleological order in which the various descriptions of action can be arranged indicates which end is ultimately to be achieved by the action. The last link in this order thus indicates the agent's intention.

Of course, the Question of 'Why?' can also be raised at the last link of the teleological order listed here: Why does the man poison the residents of the house? In order to actually bring the ever-progressing series of Questions of 'Why?' to an end, a desirability-characterisation must provide the final answer at the end of each such series. ${ }^{47}$ It either consists in the reference to certain institutions or, in Aristotelian terms, in the ultimate goal of all action, the good itself or eudaimonia. ${ }^{48}$ Teleological explanations of action thus generally take the following form:

(TE2): A $\varphi$-s, in order to $\chi, \ldots$, in order to $\psi$, where $\psi$ is a desirability-characterisation, so that $\psi$-ing either refers to an institution through which the relevance of $\psi$-ing becomes intelligible regarding the agent's conduct of life, or consists in happiness itself.

But what relevance do teleological explanations of action now have for theories of narrative identity? This is what I shall discuss in the following section.

\section{Narrative Explanations of Action}

I claim that teleological explanations of action are essentially narrative explanations of action as understood by Lamarque. Why should this be the case? As a recap, Lamarque indentifies the following characteristics and properties of narrativity:

(1) Stories are told, they are not simply found.

(2) In the context of a story, at least two events are presented and related to each other.

(3) The relationship in which these events are presented must have a temporal component.

\footnotetext{
${ }^{46}$ See Börchers, op cit., p. 101. On the role of knowledge about my doing, see Anscombe, op. cit., pp. $13-15$.

47 See Anscombe, op cit., p. 72.

${ }^{48}$ Hence, traffic regulations, for example, could be seen as such an institution: Why do I raise my arm? - To give a sign.-Why? - To signal to the driver that he is allowed to drive. - Why? —... At some point, this series of Questions of 'Why?' may be ended by referring to the continuity of the traffic order. For this makes the significance of my action (among the various descriptions of action) clear, its "place [...] within our conduct of life" (Börchers, op. cit., p. 109; my translation) intelligible. For a detailed analysis of the desirability-characterisation of actions, see Anscombe, op. cit., pp. 72-4. Regarding eudaimonia as the ultimate goal of all action see NE I, 1; 1094a1-4 and NE I, 5; 1097a20-21.
} 
When we describe actions teleologically, we are telling a story in this minimal sense. An example:

Student Emma: Emma moves her eyes from left to right regularly. At equally regular but longer intervals, she moves her hands in a certain way. At irregular intervals, she moves her hands so that they grasp certain objects in front of her and then they continue to move in such a way that these objects are moved in a certain manner.

We can describe Emma's movements within the framework of a teleological explanation of action as such: Why does Emma move her eyes?-In order to read.Why does she move her hands?-In order to turn to the next page.-Why does she grab certain things and move them in certain ways?-In order to add highlights and comments. - Why does she do all this?-In order to read a text by Anscombe.Why? - In order to write a term paper on Anscombe's theory of action.-Why? To progress in her course in philosophy-Why? — To get a good degree-Why?To earn a lot of money later on-...

This (or something like that) is how we can make Emma's movements intelligible. Of course, Emma can have different goals in her actions and the appropriate explanation of her actions will focus on what ultimately makes Emma move her eyes and hands in the described manner. For example, her reading the text and progressing in her academic studies may also serve to appease her upset mother. In this respect, the last link in the chain of Questions of 'Why?' that we can give to explain Emma's actions will refer to certain institutions, such as money, family or university in general. ${ }^{49}$

Now why do explanations of this kind fulfil the minimal requirements for narrativity as described by Lamarque? When we describe Emma's eye and hand movements teleologically, we put them in a temporal order. The individual descriptions of action are only ever intelligible with reference to the next further description of action. This next further description also provides a further temporal context: The eye and hand movements become intelligible in the context of the temporally further-reaching action of reading, which in turn becomes intelligible in the context of the temporally further-reaching action of studying, and so on. Hence, teleological explanations of action fulfil minimum conditions (2) and (3).

But what about (1)? Do actions not simply occur and are explanations of action therefore not found rather than told? No, because here a careful distinction is crucial between what occurs 'in the world' on the one hand and how we describe these events on the other. While Emma's movements of her eyes and hands occur 'in the world', we pick them out through various descriptions. However, we do not simply find these descriptions, as Anscombe also demonstrates regarding the relativity of description of actions. ${ }^{50}$ While only one event takes place, we are able to pick out

\footnotetext{
${ }^{49}$ For a similar point, see MacIntyre, op. cit., pp. 239-241.

50 See Anscombe, op cit., p. 37. Regarding the relativity of description of actions see Donald Davidson, "Agency," in Donald Davidson (ed.), Essays on Actions and Events (Oxford: Oxford University Press, 2001 [1971]), 43-62, p. 50 and regarding the distinction between the levels of type and token see Donald
} 
that one event using different descriptions. There is not just one appropriate description of Emma's movements. While there is only one token that can be describedthe event - there is a multitude of types, i.e. explanations, with the help of which we can pick out this event. As Lamarque points out for stories: "Narratives are stories that only exist when they are told." 51 The same applies to teleological explanations of action. The respective events exist independently of our description. However, the descriptions themselves need a descriptor just as stories need a narrator. In conjunction with a temporal order, these descriptions - as Lamarque shows-become narratives in a minimal sense.

At this point, we should consider two possible objections. The first one is this: With reference to what I have said here in conjunction with my action-theoretical discussion, one might object that I rely on Anscombe's theory of action to support my thesis, and at the same time my approach runs contrary to it. This is because Ancombe advocates a coarse-grained approach to the individuation of action, whereas I-according to the objection-must advocate a fine-grained approach. Again, consider the man pumping poisonous water into a tank to kill the residents of a house. Anscombe claims that the pumping and the poisoning simply is the killing. However, now one could believe that I have claimed that the pumping of the man leads to the poisoning of the water and this in turn leads to the killing of the residents. In this respect, I would take a fine-grained approach to action individuation as opposed to Anscombe's coarse-grained one. ${ }^{52}$

But this objection is not sound because it, too, does not take the type-token distinction seriously. On the token level, one happening takes place: A man pumps, which leads to the water supply of a house being poisoned, which leads to the residents being killed. We can now describe this happening on the token level linguistically and thereby we operate on the type level. For this purpose, we have various descriptions of action at our disposal. With the help of these, we always tell the same story. However, we can tell this story in different ways. And depending on which description of the action we choose ("The man pumps", "The man moves his arm", "The man poisons the residents", "The man poisons the residents by moving his arm"), we can highlight different aspects of his action. So, by taking the type-token distinction seriously, we see that-in line with Anscombe (and many other philosophers of action) - I am taking a coarse-grained approach to action individuation. The man performs one action (the story of which in some cases we can split into different sub-stories), which we can describe in different ways by choosing different versions of the same story of his action: the arm movement version, the pumping version, the poisoning version, the killing version, the revenge version, and so on.

\footnotetext{
Footnote 50 (continued)

Davidson, "Mental Events," in Donald Davidson (ed.), Essays on Actions and Events (Oxford: Oxford University Press, 2001 [1970]), 207-225, pp. 209-215.

51 Lamarque, op cit., p. 404.

${ }^{52}$ I thank an anonymous reviewer for bringing this possible objection to my attention.
} 
The second objection leads us back to the use of narrative explanations of action regarding our conception of the self. The objection is something like this: "All right", the critic might say at this point, "it may well be that teleological explanations of action are a certain kind of narrative. But as they are construed here, they are just a minimal kind of narrative. As Lamarque has already shown, these can be usefully applied to the concept of personal identity. But Lamarque has also claimed that they can't tell us anything interesting about ourselves."

Upon closer examination, however, it becomes clear that Lamarque only seems to have causal explanations in mind here: "representing actions in a causal and temporal sequence-seemingly the most straightforward if not the only way to do so-is in this minimal sense indeed to represent them in a narrative." 53 As long as the story we tell in the context of explanations of action is merely the causal story leading up to an action, it in fact cannot be particularly informative.

The teleologist's explanations, however, are different, because within the framework of such explanations of action, we not only are told which events were causally relevant to the respective agent performing a particular action. Rather, we learn what purposes the agent is pursuing and thus gain insight into whom we are dealing with. As the last link in a chain of Questions of 'Why?', the agent's purposes become intelligible. This makes an agent's particular action intelligible in the context of further-reaching descriptions of action. Ultimately, these purposes refer to certain concepts of happiness held by the agent or to certain institutions. This in turn enables us to see what is of value to the respective agent ${ }^{54}$ - what is the end that Emma is pursuing with her eye and hand movements? Is it the prospect of earning a lot of money with her philosophy degree? Or is it rather an attempt to please her mother by taking her studies seriously?

There is, of course, some question as to how far-reaching these stories are that we tell about ourselves. Every day we perform an innumerable number of actions. Is there a single story that synthesises all of them? Or is it just that we come up with a new story for every action? It seems to be obvious that the individual actions of an agent can only be made intelligible in the context of further actions. Most purposes can only be achieved by a multitude of actions. Of course, it is possible that

\footnotetext{
53 Ibid., p. 402; my emphasis. In addition, see p. 406 ("Given that a narrative just is the ordering of a sequence of events, including the placing of events in causal sequences, it is a truism that narratives can explain. What better explanation than causal explanation?").

54 See also ibid., p. 406 ("A narrative can explain why someone acted as he did; it can explain people's values; it can forge connections; it can weigh priorities."). See also David Lumsden and Joseph Ulatowsky, "How Self-Narratives and Virtues Cause Actions", in Joseph Ulatowsky and Liezl van Zyl (eds.), Virtue, Narrative, and Self: Explorations of Character in the Philosophy of Mind and Action (London: Routledge, 2021), 69-90, who invoke the narrativity of action explanations in support of causal theories of action, arguing for the proximity of a narrative conception of action to virtue ethics. For somewhat similar projects approximating narrativity and the causal theory of action, see Thomas Uebel, "Narratives and Action Explanation", Philosophy of the Social Sciences, 42 (2012): 31-67. For an approach to approximating historical narratives and teleological explanations of action, see Frederick A. Olafson, "History and the Concept of Action", History and Theory, 9 (1970): 265-289. Again, I thank an anonymous reviewer for bringing these papers to my attention, which are pursuing similar projects as I am here.
} 
we achieve any purpose to $\psi$ merely by $\psi$-ing - that is, by merely describing this activity as $\psi$-ing. ${ }^{55}$ But this is a truism and does not make the action intelligible. It only becomes intelligible through the role that a certain behaviour plays in the context of narrower and broader descriptions of the agent's actions. In this respect, explanations of action are always stories that - through the purpose pursued-are in a certain sense self-contained, but which at the same time are part of a more extensive story that covers the span of a life or can even go beyond it. For if we submit our lives to the purpose of a cause that is 'greater than we are', then our actions ultimately become intelligible only in light of a story that extends over more than a single life.

Equally of course, there are stories that have discontinuities: that of the CEO of a tech company who has retreated to a lonely cabin in the Appalachians, or that of the homeless man who becomes a celebrated opera singer after his magnificent voice is discovered by coincidence. The various stories that can be told on either side of such a rupture often have little in common. How different the story of the CEO will be compared to the story of the hermit. It is difficult at this point to still speak of the same person let alone the same story. ${ }^{56}$ But still: even the discontinuities only become intelligible on the basis of a story, because here, too, it is ultimately certain actions that explain the transition from one story to another.

However, that our behaviour becomes intelligible as actions through stories does not mean that these stories have to be of a special literary quality. Some stories are thrilling, intriguing or horrifying enough in order to tell them to a larger audience with the proper literary skill. If they are true, we encounter them, for example, as biographies, if they are only imaginary, as novels. But most of our stories, as Lamarque remarks, are insignificant and uninteresting. ${ }^{57}$ But they are stories nonetheless. After all, who said that stories have to be interesting or that they must 'get under your skin'? Most of us live perfectly normal lives about which perfectly normal, i.e. uninteresting, stories can be told. ${ }^{58}$ That is why, in most cases, it is incorrect to talk about genres in terms of our life stories as MacIntyre does. ${ }^{59}$ Most of our stories will be ones that precede any

\footnotetext{
55 This also makes it clear that this question is ultimately only one of terminology and insofar does not concern an actual matter, but only the description of the matter. In this respect, however, the terminological level does seem to be quite relevant, because it is only through this that we can conceive ourselves as acting agents. For a contrary position on the relevance of the terminological dimension, see for example Derek Parfit, "Personal Identity," The Philosophical Review 80 (1971): 3-27.

56 For an analysis of how strong the narrative unity needs to be in terms of the continuity of a person (in the sense of the CEO now living in the Appalachia) on the one hand and a self (either in the sense of the CEO or the hermit) on the other, see Marya Schechtman, "Stories, Lives, and Basic Survival: A Refinement and Defense of the Narrative View," Royal Institute of Philosophy Supplement, 60 (2007): 155-178, in particular pp. 167-171.

57 See Lamarque, op. cit., p. 407.

58 At this point it seems reasonable to mention that our lives are lived and stories about them are told. Whoever claims that we live our stories (see MacIntyre, op. cit., p. 246) is blurring the distinction between the type and token level. See also Tim Henning, Person sein und Geschichten erzählen. Eine Studie über personale Autonomie und narrative Gründe (Berlin/New York: de Gruyter, 2009), p. 236 regarding the issue that the description must be narrative and not the life in the sense of the events taking place.

59 See MacIntyre, op. cit., p. 245.
} 
genre. Genres are a literary category. Stories can be classified by genre, but stories that are as boring and uninteresting as most of those that can be told about our actions and lives-such stories have no (or neglectable) literary quality. Why should we try to classify them in a genre?

But if most of our stories are not worth telling, why should we bother with them? We shouldn't; at least not from a literary point of view. As I said before, to apply literary vocabulary to our life stories is unnecessary, they are, in Lamarque's terms, 'not worth' engaging with in this way. Yet stories enable us to conceive our behaviour as action, only they enable us to interpret mere movements as actions in light of rationality. Only through them can we perceive ourselves as acting rationally. Even if our stories are uninteresting and trivial for the general public, only they can make us intelligible to ourselves and to others. ${ }^{60}$

\section{Conclusion}

I first examined Lamarque's criticism of narrative concepts of identity. He shows that stories, understood in a minimal sense, are not found but told and that they establish a temporal relationship between at least two events.

I then examined the concept of teleological explanations of action. Considering the problem of deviant causal chains that causalists are confronted with, they are at least a serious alternative to causal explanations of action. In the course of examining the problem of deviant causal chains, I also attempted to render plausible the irreducibility of teleological explanations of action to causal ones.

Subsequently, I have outlined some features of teleological explanations of action. They consist in a chain of Questions of 'Why?', through which a certain behaviour is made intelligible as an intentional action by means of different descriptions of action. The last link in this chain of Questions of 'Why?' refers to a certain desirability-characterisation, which either consists in happiness itself or in certain institutions through which the desirability of a certain goal becomes intelligible.

Finally, I have defended the idea that teleological explanations of action are essentially narrative explanations of action because they meet Lamarque's minimal conditions of narratives. Against Lamarque, I have made the case that these kinds of narratives are not trivial with respect to our personal identity but, on the contrary, are the prerequisite under which we can perceive ourselves as rational agents.

Declarations The author has no relevant financial or non-financial interests to disclose.

The author has no conflicts of interest to declare that are relevant to the content of this article.

The author certifies that he has no affiliations with or involvement in any organization or entity with any financial interest or non-financial interest in the subject matter or materials discussed in this manuscript.

The author has no financial or proprietary interests in any material discussed in this article.

Funding Open Access funding enabled and organized by Projekt DEAL.

\footnotetext{
60 A similar approach is taken by Henning, op. cit., especially pp. 9-10 and p. 22. Regarding the idea that through stories we can conceive not only ourselves as rational agents, but also others, see ibid., p. 18.
} 
Open Access This article is licensed under a Creative Commons Attribution 4.0 International License, which permits use, sharing, adaptation, distribution and reproduction in any medium or format, as long as you give appropriate credit to the original author(s) and the source, provide a link to the Creative Commons licence, and indicate if changes were made. The images or other third party material in this article are included in the article's Creative Commons licence, unless indicated otherwise in a credit line to the material. If material is not included in the article's Creative Commons licence and your intended use is not permitted by statutory regulation or exceeds the permitted use, you will need to obtain permission directly from the copyright holder. To view a copy of this licence, visit http://creativecommons.org/licen ses/by/4.0/.

Publisher's Note Springer Nature remains neutral with regard to jurisdictional claims in published maps and institutional affiliations. 